\title{
Impact of high fat diets, prebiotics and probiotics on gut microbiota and immune function, with relevance to elderly populations
}

\author{
Yue Liu, Glenn R. Gibson and Gemma E. Walton* \\ Department of Food and Nutritional Sciences, Whiteknights, University of Reading, Reading, UK
}

\begin{abstract}
According to WHO, the number of people over 60 years of age is set to rise to 2 billion by 2050. Dysbiosis of microbial composition and impaired immune function have been observed in elderly persons compared to younger adults. As a result, the aging population has a higher disease risk than other age groups. In addition, high fat intakes have been observed to exert negative effects on microbial composition and immune function in murine studies. Elderly people have higher fat intakes than recommended levels, and this may make them more vulnerable to disease risk. Therefore, the impact of high fat consumption on elderly populations may be of relevance. Prebiotics and probiotics have been shown to have positive effects on microbiota composition and immune function in the elderly. This review describes aged-related changes in gut microbiome of elderly persons. It will also summarise studies concerning the impact of prebiotics, probiotics and high fat diets on microbiota composition and immune function.
\end{abstract}

Keywords: Aging, microbiota, immune markers, prebiotics, probiotics, high fat

\section{General background on gut microbiology}

\subsection{Microbiota of the gastrointestinal tract}

Over 1000 bacterial species exist within the human gut [1] with more than 50 bacterial genera being described [2]. The large intestine harbours the highest numbers of bacteria in the gastrointestinal tract, at around $10^{11}$ to $10^{12}$ cells per gram. Decreased transit time, readily available nutrients and a favourable $\mathrm{pH}$ provide a suitable environment for microbial growth in the large intestine [3].

\footnotetext{
*Corresponding author: Gemma E. Walton, Department of Food and Nutritional Sciences, Whiteknights, PO Box 226, University of Reading, Reading RG6 6AP, UK. Tel.: +44 0118378 8718; Fax: +44 0118378 7708; E-mail: g.e.walton@ reading.ac.uk.
}

\subsection{Substrate and products of microbial fermentation}

There are two main fermentation substrates from the diet: non-digestible carbohydrates and undigested proteins from the upper gastrointestinal tract [4]. Carbohydrates that escape hydrolysis and absorption in the upper colon are principal substrates for bacterial growth. Saccharolytic fermentation is mostly from species belong to the genera Bacteroides, Ruminococcus, Bifidobacterium, Lactobacillus, Eubacterium, and Clostridium [5]. The end-products of carbohydrate fermentation include short chain fatty acids (SCFAs), mainly, acetate, propionate and butyrate [6-8], lactate and other metabolites such as $\mathrm{CO}_{2}, \mathrm{H}_{2}, \mathrm{CH}_{4}$ and ethanol [9]. Amino acids, peptides and proteins, are also 
important substrates for bacterial growth. Proteolytic fermentation is mostly from species belonging to the genera Bacteroides and Clostridium [10]. The endproducts of protein fermentation include branched chain fatty acids such as iso-butyrate, nitrogenous and sulphur-containing compounds. Some are toxic to host health, such as ammonia and amines [10]. Increased concentrations of ammonia have been suggested to be responsible for hepatic coma syndrome, a loss of consciousness, which may stem from impaired liver function [11]. High levels of amines are also related to increased risk of bowel diseases, such as colorectal cancer [12]. In addition, high fat diets have also been seen to have an impact on the microbiota [13-15]. Although most dietary fat is digested in the small intestine, there are still small amounts entering the large intestine [16-18].

\section{Definition and history of probiotics and prebiotics}

As the gut microbiota can be influenced by diet, consumers may positively modulate their microbiome through consumption of specific functional foods, namely probiotics and prebiotics. The first scientific introduction of the probiotic concept was by Metchnikoff at the beginning of the 1900 s. In his thesis called the 'Prolongation of Life', he hypothesised that longevity in Bulgarian peasants was associated with their large intakes of fermented milk containing health-promoting microorganisms (now known as probiotics) [19]. In 2001 and 2002, the concept of probiotics was proposed by a WHO/FAO working party as 'live microorganisms that, when administered in adequate amounts, confer a health benefit on the host $[20,21]$ '.

The concept of prebiotics was introduced when Gibson and Roberfroid [22] observed that certain non-digestible oligosaccharides were selectively fermented by bifidobacteria. A prebiotic is 'a nondigestible food ingredient that beneficially affects the host by selectively stimulating the growth and/or activity of one or a limited number of bacteria in the colon that can improve host health [22]'. Subsequently, due to improved knowledge of the gut microbiota composition, a dietary prebiotic has been defined as 'a selectively fermented ingredient that results in specific changes, in the composition and/or activity of the gastrointestinal microbiota, thus conferring benefit(s) upon host health [23]'.

\section{What happens as we get older?}

Currently, there is an increase in life expectancy leading to an expanding aged population. According to WHO, since 1980, the worldwide population of adults aged over 60 has doubled and this number will increase to 2 billion by 2050 [24]. Aging is defined as 'the regression of physiological function accompanied by advancement of age [25]'. The aging process leads to changes in the functional ability of many organs and tissues, such as within the gastrointestinal tract and immune system [26, 27]. Dietary components, which are fermentation substrates for intestinal microbiota, are able to inevitably affect the diversity, numbers and activities of colonic bacteria. Their metabolites may subsequently influence the immune system [28]. Age-related changes can be associated with increased disease risk.

\subsection{Changes in gastrointestinal tract in elderly population}

Understanding changes within the gastrointestinal tract of the elderly is important as manipulation of this system may aid in maintenance of host heath. Older people have an increased threshold for taste and smell than younger adults [29]; consequently they often find foods bland and tasteless [30]. Furthermore, loss of teeth can lead to difficulties in masticating [31] and swallowing [32]. Therefore, there are problems associated with the diet of older people [33]. In addition, intestinal motility is reduced, possibly leading to faecal impaction and constipation [34-36]. Decreased faecal weight is indicative of physiological gastrointestinal tract changes, associated with reduced transit times and bacterial metabolites in older persons [37-40]. A reduced transit time can also lead to increases in detrimental proteolytic bacteria metabolites, such as ammonia and amines, which can be toxic to host gut health $[9,33]$.

\subsection{Changes in immune function in elderly populations}

A compromised immune function, loosely defined as immunosenescence has been observed in elderly populations, where the aging process adversely influences immune functionality [41]. Immunosenescence is characterised by a decreased immune response to exogenous infectious agents and 
increased response to endogenous signals. Additionally, increased levels of proinflammatory cytokines, such as interleukin-1 $\beta$ (IL-1 $\beta$ ), IL-6, and tumour necrosis factor- $\alpha$ (TNF- $\alpha$ ), decreased phagocytosis and natural killer (NK) cell activity have been observed in elderly populations [42, 43].

During aging, clearance of apoptotic cells is impaired and not complete, resulting in an accumulation of necrotic cells, with the production of autoantigens such as nucleic acids [44]. Autoimmune and abnormal immune responses to the host are observed during immunosenescence. In addition, naive B cells, generated in the bone marrow, decrease with increasing age [45], resulting in a reduced ability to protect the host against infectious agents. Furthermore, elderly populations have been observed to have intrinsic B cell dysfunction or declined CD4-T cell helper function [46]. The $\mathrm{T}$ cell compartment has been observed to be reduced due to a lowering in size and cellularity of the thymus. Such alterations may result in persistent viral infections and chronic disease by making cells more exposed to antigens [47].

\subsection{Intestinal microbiota changes in an aging population}

Microbiota equilibrium is important in maintaining host health and providing a natural defence against invading pathogens. However, because of age-related changes in the diet, immune function and physiology of the gastrointestinal tract microbiota, dysbiosis has been observed in the elderly [28]. For example, culture based studies have shown decreased Bacteroides in elderly compared to younger adults $[39,48]$. Also, by using fluorescence in situ hybridisation (FISH) Mueller et al. [49] found this trend in Italian elderly. Furthermore, increased Bacteroides have been reported in Austrian elderly patients [50] and Finnish elderly subjects [51] by using molecular methods.

Bifidobacterium is an important genus thought to be involved in health promotion [28]. A reduction of bifidobacteria in terms of number and diversity is one of the most notable changes in elderly populations and has been reported in studies using traditional culture and modern molecular methods [39, 48, 49, 52-55]. These changes may result from declined adhesion to the intestinal mucosa, although it is not sure whether this is due to changes in bifidobacteria or in the chemical component and structure of intestinal mucosa [56, 57]. Overall, this may lead to a reduction in gut function and immune response, and potentially increased susceptibility to disease [33].

Clostridium cluster XIVa (Clostridium coccoides group) and cluster IV (Clostridium leptum group) are important bacterial groups within the gut microbiota. A large proportion of bacteria producing butyrate, a SCFA beneficial to gut health, belong to these two clusters [58, 59]. A decrease of Clostridium cluster XIVa in elderly persons was reported by Biagi et al. [38]. Mueller et al. [49] and Makivuokko et al. [51] found that such a change was dependent on the nationality of the volunteer.

An increase in facultative anaerobes, such as streptococci, enterococci and enterobacteria is a well confirmed age-related occurrence $[39,49,51,52$, $60,61]$. The enterobacteria group are considered to be potentially detrimental; as such these are implicated in pathogenesis when the host immune response alters during the aging process.

\subsection{Age-related changes and disease}

As mentioned above, aging leads to gastrointestinal tract changes in terms of the gut microbiota and immune function. Immunosenescence is observed in elderly persons with dysregulated immune response [42, 43]. Elderly populations also have declined colonic mucin production and elevated inflammatory status, increasing the potential for bacteria to adhere to gut epithelial cells [62]. Changes in the gut microbiota may increase susceptibility to pathogenic infections [62], which may lead to immune dysregulation. The triadic relationship between an impaired gastrointestinal tract, imbalanced gut microbiota and chronic inflammation is significantly associated with increased disease risk in elderly persons, such as infections, inflammatory bowel disease (IBD) and colorectal cancer (CRC) [62] (Fig. 1). IBD is a chronic disorder characterised by inflammation and ulceration of the gastrointestinal tract. Age-related changes in microbiota, such as reduced gut microbiota diversity has been observed in IBD patients [62-64]. In addition, decreased levels of Faecalibacterium prausnitzii has been seen in Crohn's disease patients $[65,66]$. An imbalance between proinflammatory and immunoregulatory cytokines found in the elderly also may contribute towards IBD [67]. Elderly people have an increased risk of CRC; one reason for this could be gut microbiota dysbiosis and immune dysfunction. Decreased levels of short chain fatty acids, especially butyrate, are found 


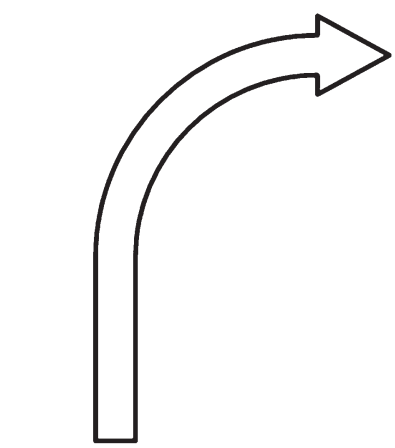

Age-related gastrointestinal tract

(Intestinal motility $\downarrow$, transit time $\downarrow$, malnutrition, host immune reactivity)

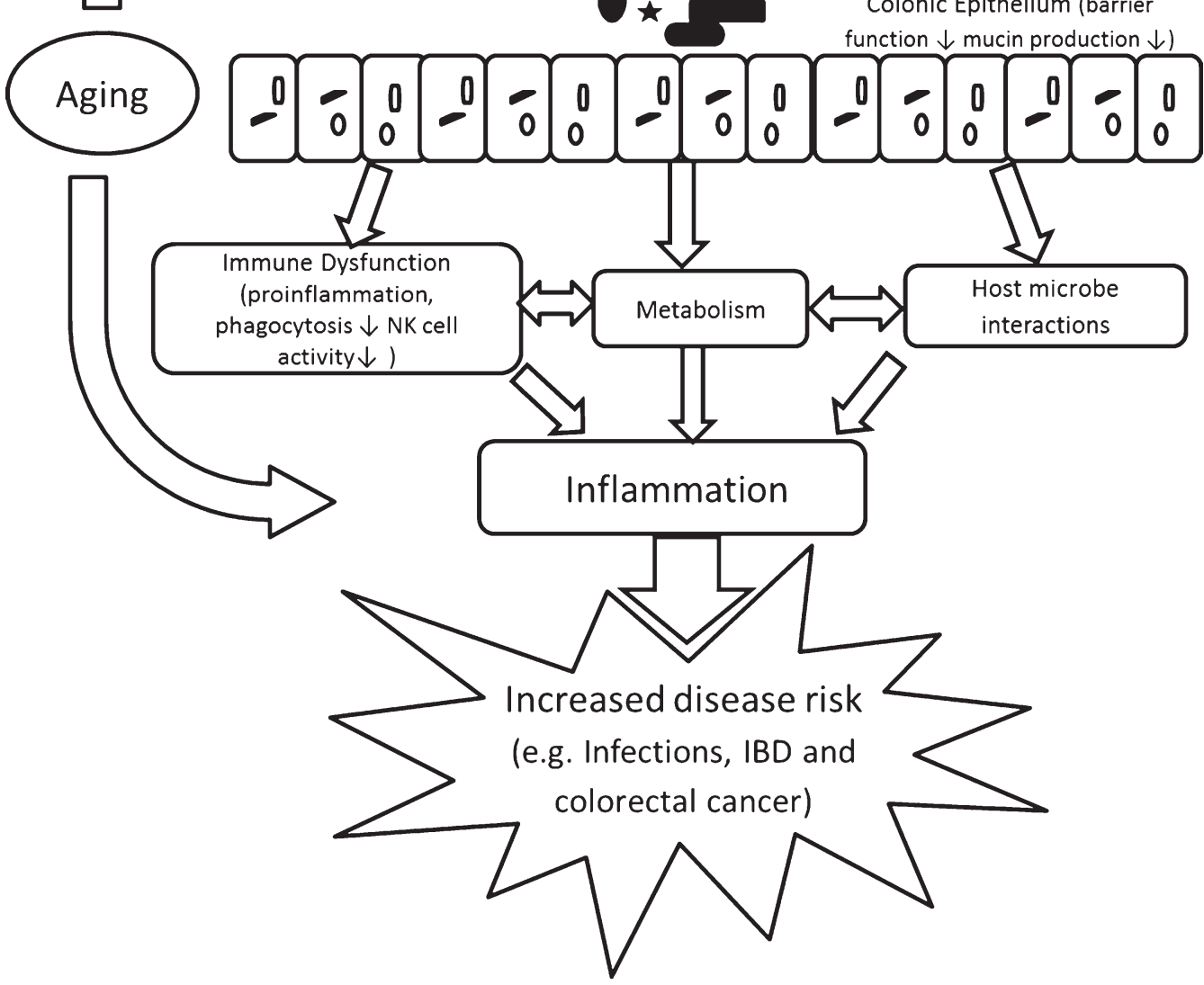

Fig. 1. Relationship between the impaired gastrointestinal tract, imbalanced gut microbiota, and chronic inflammation is significantly associated with increased disease risk in elderly populations, such as infections, inflammatory bowel disease (IBD) and colorectal cancer (CRC). Adapted from [154].

in western elderly populations and are considered relevant to CRC risk. Butyrate shows anticarcinogenic capacity by stimulating cell differentiation and apoptosis as well as preventing cell proliferation [4]. A decrease in butyrate levels is associated with declined numbers of Faecalibacterium prausnitzii and Clostridium cluster XIVa, a group containing many known butyrate producers [68]. Chronic inflammation related to immune dysfunction in the elderly may also contribute to CRC risk [62].

\section{Effects of prebiotics and probiotics in elderly persons}

\subsection{Effects on microbiota composition}

Prebiotics and probiotics can modulate colonic microbiota composition in elderly people by increasing bifidobacteria and may decrease other bacteria, findings from such studies have been summarised in Table 1. Well-tested prebiotics include short-chain 
fructooligosaccharides (scFOS), inulin and galactooligosaccharides (GOS). One tested dose was $2.64 \mathrm{~g} \mathrm{B-GOS}$ which acted as prebiotic, this was taken for 10 weeks by healthy elderly [28]. Studies of other prebiotics (scFOS and inulin) are often used at higher doses than that of B-GOS [34, 69-71]. To study specific bacterial number changes, enumeration techniques, traditional culture methods, fluorescent in situ hybridisation (FISH), real-time polymerase chain reaction (PCR) may be applied. To study stability and diversity of microbiota changes, denaturing gradient gel electrophoresis (DGGE) can be used. For example, to investigate the impact of GOS on the faecal microbiota, real-time PCR was used by Walton et al. [71] and DGGE by Maukonen et al. [72]. According to their results, GOS exerted positive effects on microbiota composition and host health in the elderly by increasing numbers of bifidobacteria. However, diversity was not assessed. Compared to other prebiotics, B-GOS may be more selective in stimulating the growth of bifidobacteria, as the prebiotic is produced by enzymes (three $\beta$ and one $\alpha$ galactosidase enzyme) from a probiotic strain Bifidobacterium bifidum NCIMB 41171 using lactose as a substrate [73]. Similarly, composition of the microbiota in elderly persons has been modulated through administration of selected probiotics (e.g. Bifidobacterium and Lactobacillus spp.) (Table 1). Daily administration of $L$. case $i$ has been observed to reduce numbers of Enterobacteriaceae, some of which are pathogenic [74]. Different $L$. case $i$ strains have varying functions and health benefits. Even within the same species, strains may promote activities of different bacteria [75-78] and lead to a range of health promoting properties [79]. Synbiotics, a mixture of prebiotics and probiotics, also have shown modulatory effects on colonic bacterial composition in the elderly (Table 1). By using synbiotics, survival of probiotics in the colon can be reinforced and modulatory effects fortified [80, 81]. Synbiotic, Bifidobacterium bifidum BB-02, Bifidobacterium lactis BL-01 and inulin not only stimulated specific probiotic numbers, but also total bifidobacteria and lactobacilli [80]. This also occurred with Lactobacillus acidophilus and lactitol [81].

\subsection{Effects on immune function}

Prebiotics and probiotics may additionally help regulate immune function of elderly persons, this has been observed through altered immune mark- ers such as NK cell and phagocytic activities, such studies have been summarised in Table 2. Prebiotics, including B-GOS and scFOS, may regulate immune responses in the elderly by down-regulating proinflammatory cytokines, hence leading to positive effects on the immune system. For example, studies indicate that test prebiotics could reduce production of proinflammatory cytokines IL- 6 and TNF- $\alpha$ in elderly people [28, 70, 82]. However, in one study, oligofructose/inulin supplemented with vitamins and protein did not show immuno-regulatory effects in elderly persons [83]. Probiotics may also modulate the immune system of elderly people e.g., L. rhamnosus HNO01 [84-87] and B. lactis HN019 $[86,88-90]$ are well studied strains. The targeted immune markers of probiotics are similar to those of prebiotics, indicating that both may share some general mechanisms. A synbiotic containing lactitol and $L$. acidophilus led to a significant increase in prostaglandin E2 $\left(\mathrm{PGE}_{2}\right)$ levels which are declined in the elderly and essential in normal physiological gut function including cytoprotection [81].

Prebiotics and probiotics exert direct or indirect effects on modulation of gut microbiota and immune function. In terms of probiotics, depending on products, a dosage range of $10^{8}$ to $10^{12} \mathrm{CFU} /$ day live microorganisms is often consumed [91]. Prebiotics (typical dose 4-8 g/d for FOS or GOS) stimulate the growth and/or activity of endogenous microbiota or probiotics when consumed. Gut microbiota can be modulated by prebiotics and probiotics through the latter's ability to compete with pathogens for nutrients and colonisation sites. For example, strains of lactobacilli have been shown to compete for colonisation sites with pathogens [92, 93]. In addition, via saccharolytic fermentation, SCFAs can be produced, mainly acetate, butyrate and propionate $[6,7]$. Prebiotic and probiotic treatment can increase saccharolytic fermentation and SCFA production, hence the colonic $\mathrm{pH}$ becomes lowered. Reduced gut $\mathrm{pH}$ encourages the survival and growth of commensal bacteria preferring an acidic environment, thus may reduce the activities of pathogens [91, 94]. The production of butyrate is important as it serves as a colonocyte energy source and regulates the growth and differentiation of cells [7]. Butyrate can also stimulate the production of mucins [95], which are required for mucous layer maintenance and epithelial protection [96], hence enhancing gut barrier function.

Tight junction protein expression and localisation can also be improved following administration 


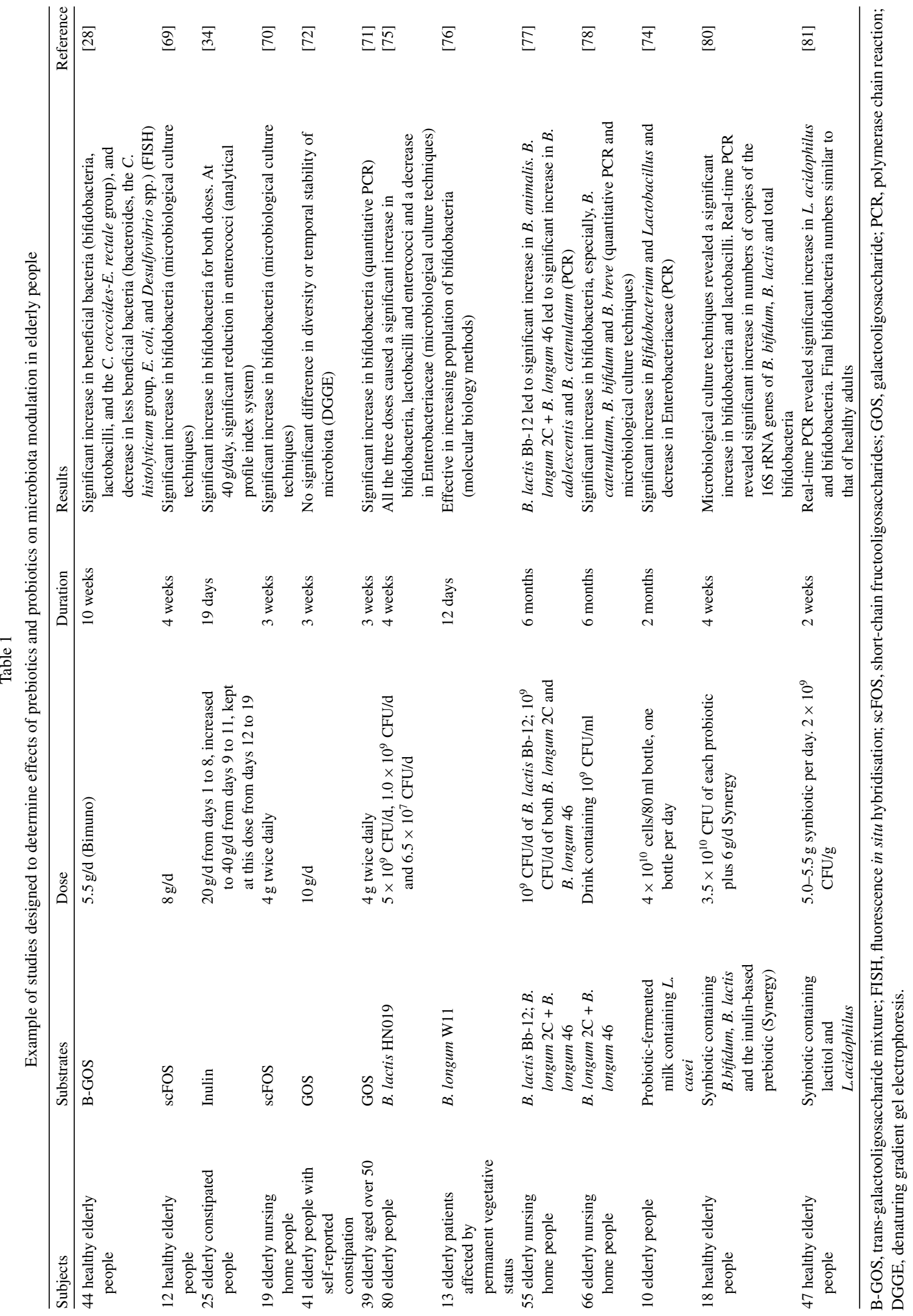




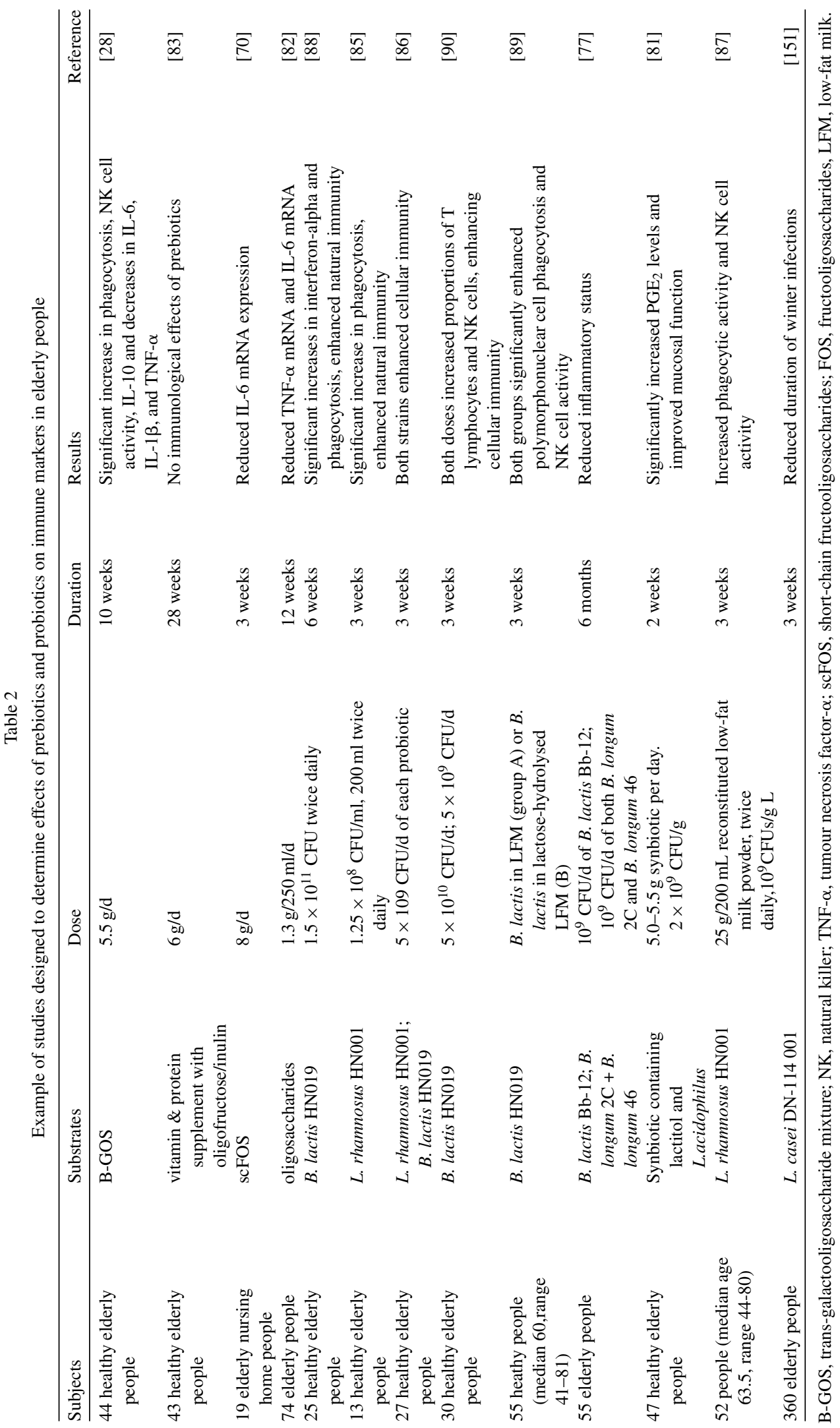


of prebiotics and probiotics [91, 97, 98], therefore improving barrier function and preventing translocation of pathogens. Antimicrobial substances, such as bacteriocins, can be produced following prebiotic and probiotic intake. These can inhibit the growth of pathogenic bacteria in vitro $[93,99,100]$ and may result in reduced infections [91]. Modulation of gut microbiota through prebiotics and probiotics may alter bacterial immune-interactive profiles. These interactions may lead to cytokine production with improved immune status [101, 102]. Fermentation products such as SCFAs can modify the activity of immune cells and enterocytes. SCFAs influence chemokine expression in intestinal epithelial cells $[103,104]$. SCFAs can modulate inflammation with pro-inflammatory IL-12, IFN- $\gamma$ and TNF- $\alpha$ being inhibited by butyrate [105-107] and immunoregulatory IL-10 being increased by acetate, butyrate and propionate [107, 108].

\section{Effects of high fat diet on elderly persons}

Age-related changes in microbiota composition and immune function in the elderly are considered to be detrimental to health. Additionally, a high fat diet has been shown to have an impact on the microbiota composition and immune function in animal models [13-15, 109]. Elderly people have higher fat intakes than recommended levels [110]. Therefore, it is worth considering the impact of fat on elderly microbiota and immune function.

\subsection{Fat intake in elderly persons}

According to Bates et al. [110], a typical elderly person's daily intake of total fat is $36.1 \%$ food energy and daily intake of saturated fatty acids is $14.2 \%$ food energy. The elderly daily intakes of total fat and saturated fatty acid are higher than the UK Dietary Reference Value (DRV), which are 35\% and 11\% food energy respectively. According to several studies, fat can contribute and improve tenderness and different flavours in food. This is relevant as the elderly often have difficulties with their teeth, and their threshold of taste and smell may become higher, thus rendering food tasteless and bland [111]. Thus, high fat foods become a feasible option for the elderly [110]. High fat intake can have an impact on the gut microbiota composition and immune function in animal models. Elevated fat intake by elderly popula- tions may make this group more vulnerable to disease risk.

\subsection{Effects of high fat diet on gut microbiota}

Most dietary fat is digested by pancreatic lipases in the small intestine; the products of this digestion are absorbed into mucosal cells and mostly re-esterified into triacylglycerol. However, there are still small amounts of fat entering the large intestine as has been shown by ileostomy studies [16-18]. In addition, the fatty acid composition of ileostomy effluent resembles that of the diet [18]. A high fat diet can alter the composition of colonic microbiota. Importantly, the most consistently observed impact of a high fat diets are decreased numbers of the Bacteriodetes phylum but increased Firmicutes (Table 3). This result, as observed in murine studies, is relatively reproducible and reliable.

The ultimate way to model the impact of a high-fat diet on humans would be in a human population; however, due to ethical considerations this is not always possible. The use of animal models offers a tempting alternative and enables tighter dietary controls to be operated. Differences in the microbiota between humans and animals can be reduced by the use of gnotobiotic animals, whereby animals are inoculated with a human microbiota. Gnotobiotic animals have not always been used in such studies, however, in the study of Respondek et al. [113], (Table 3) gnotobiotic germ-free mice were inoculated with fresh faecal samples from human, and results showed that high fat diets significantly reduced numbers of LactobacillusEnteroccocus compared to control diet. This does also match with the results of some non-gnotobiotic studies $[118,119]$. However, caution must be taken when comparing and interpreting this data from such models as differences in anatomy and physiologies to test species, (e.g. mouse) are apparent. In the following section murine high fat studies have often given rise to similar results in older humans, showing, although varied the data is useful.

As summarised from studies shown in Table 3, within the Bacteriodetes phylum, the genus, Bacteroides has been shown to decrease in most murine studies following a high fat diet [114-118]. However, within the phylum Firmicutes, specific bacterial changes are more varied. For example, Eubacterium rectale-Clostridium coccoides [114, 115], Roseburia spp. [117, 119] and Lactobacillus spp. [118, 119] decreased following high fat diets. Similarly, the 


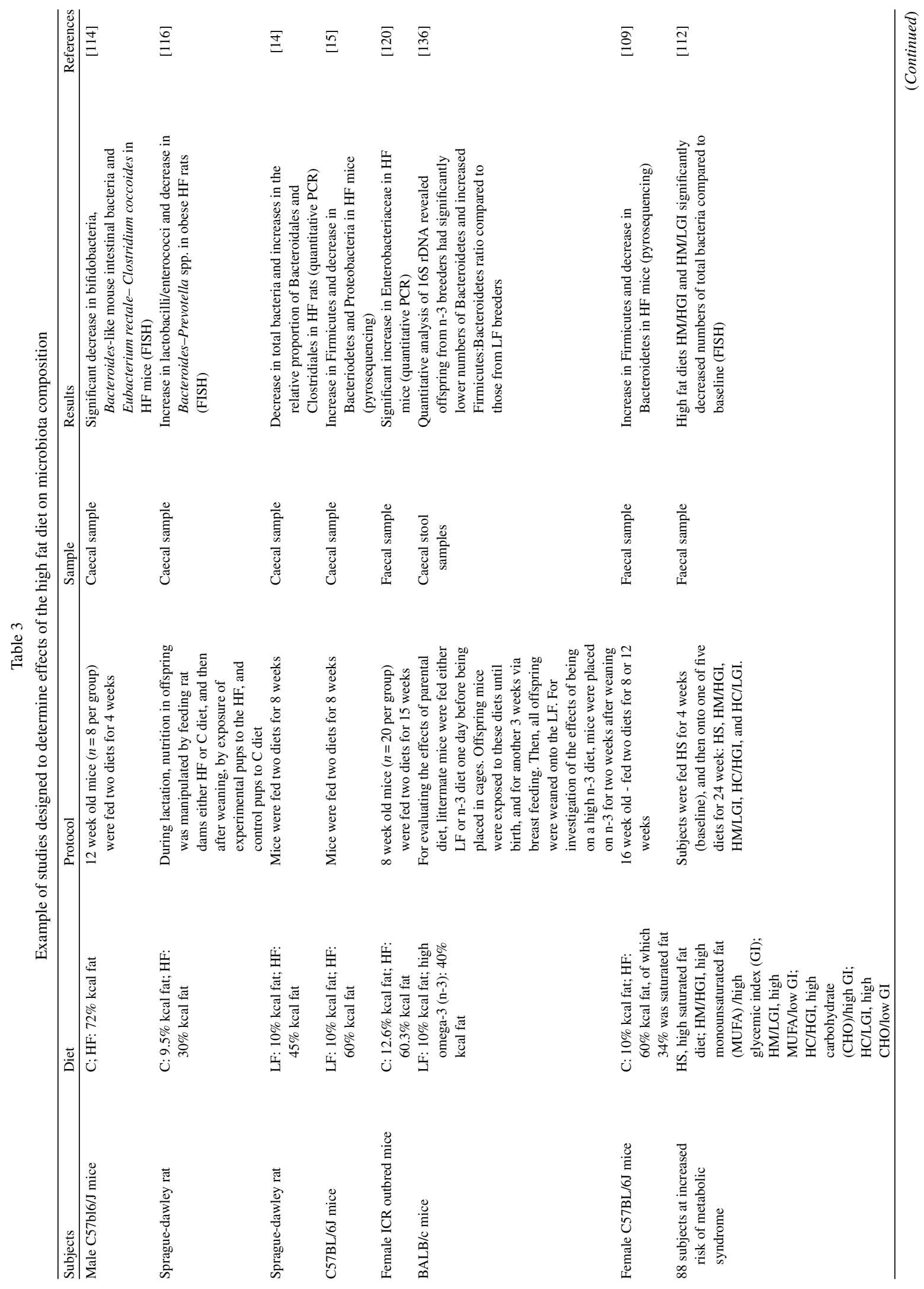




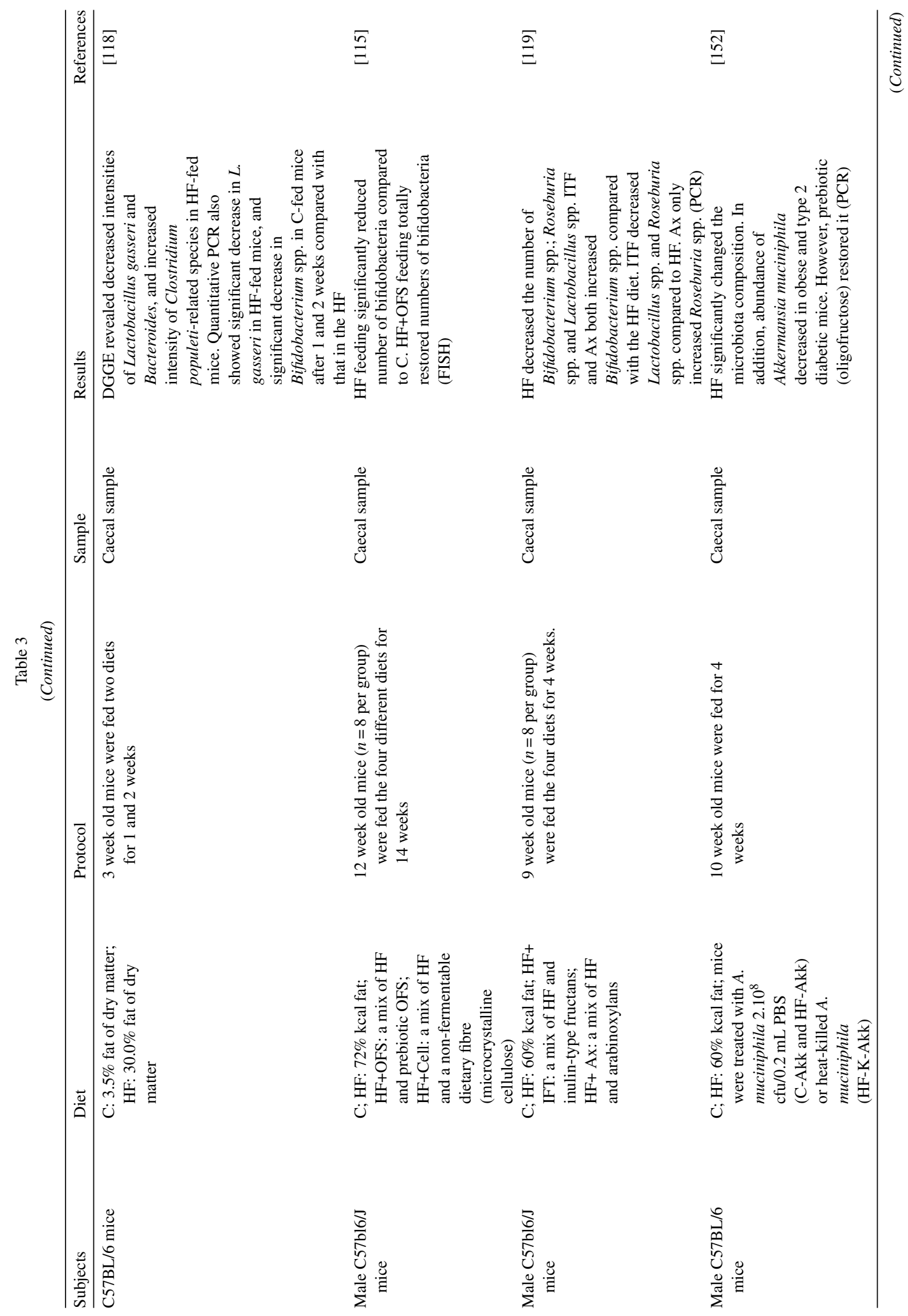




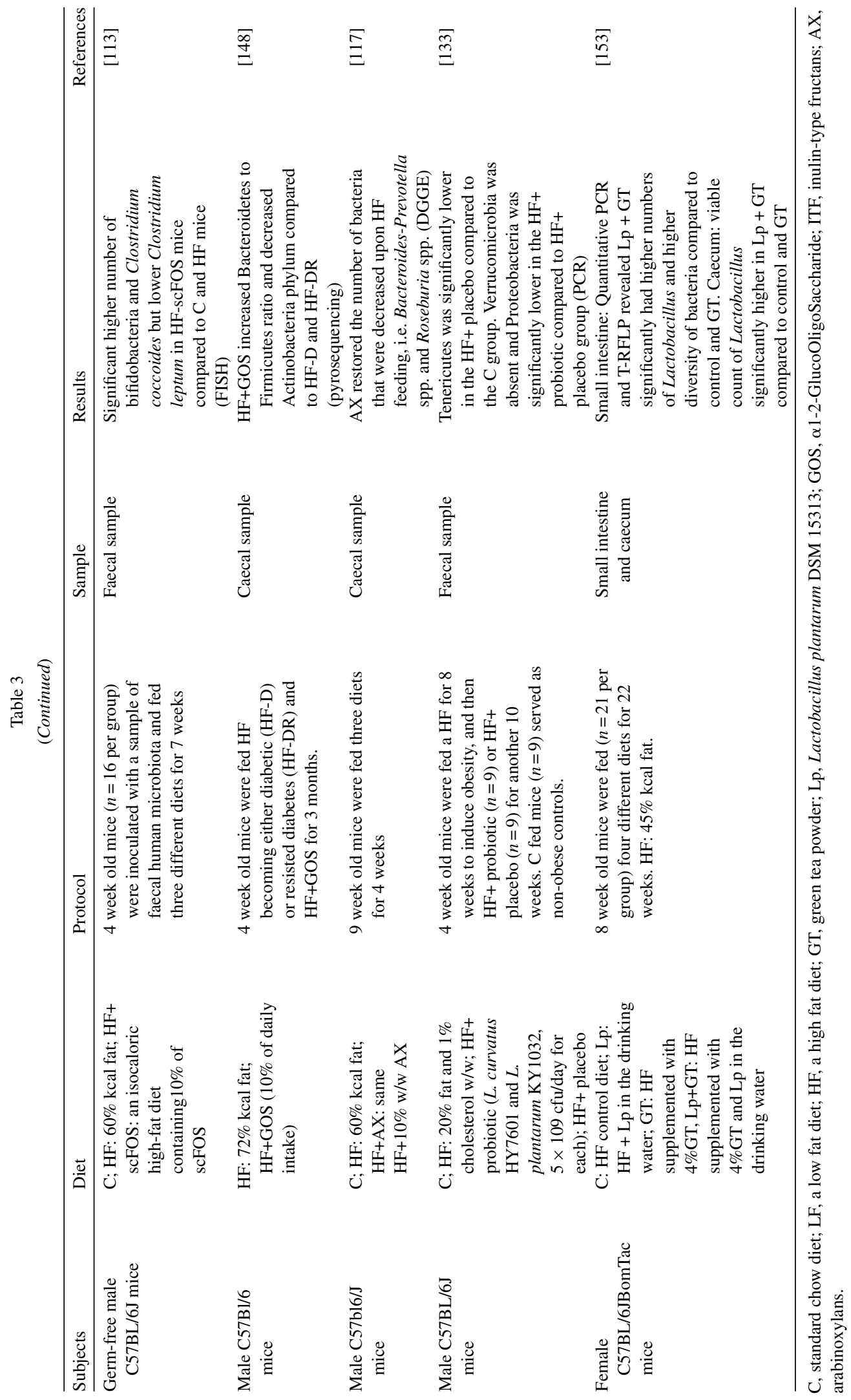


phylum Proteobacteria decreased following a high fat diet [15], however, within this phylum, Enterobacteriales increases were observed [120]. These animal study findings have similarly been observed in humans with decreases in Bacteroides [39, 48], Clostridium coccoides [38] and increases in Enterobacteriales $[39,49,51,52,60,61]$ in elderly populations.

Alterations observed in bifidobacterial numbers following a high fat diet vary (Table 3 ). In a few murine studies, numbers of bifidobacteria in caecal samples have been seen to decrease following a high fat diet $[114,115,119]$. In contrast, other studies showed different results in terms of bifidobacteria. For example, in the human study of Fava et al. [112] and murine study of Respondek et al. [113], high fat diets had no significant effect on bifidobacterial numbers in faecal samples. In the murine studies of Patrone et al. [118] and Neyrinck et al. [117], bifidobacteria in caecal samples were shown to be significantly higher following a high fat diet compared to a control group. As the bifidobacterial change following a high fat diet is inconclusive in murine studies, it may not be observed in elderly persons. The impact needs to be further investigated in human trials. Although a high fat diet may change specific bacterial numbers, total bacteria are not generally affected (Table 3). A high fat diet may result in an increased ratio of Firmicutes: Bacteriodetes, but could also impact on bacteria such as Clostridium spp., Lactobacillus spp. and Bifidobacterium spp. Such differences may be due to: 1 , subject group/animal; 2 , age groups; 3 , type and content of fat; 4, treatment protocol (duration and sample size); 5 , techniques used to enumerate bacteria. Most studies have used mice as the experimental model, because they are inexpensive and easily operated, furthermore they can receive much higher fat content diets compared to humans. Also in human studies, the overall diet is more difficult to control.

Many human studies have focused on comparisons in faecal microbiota between obese and normalweight subjects. Most showed differences at the phylum level, and some studies at the genus and species level. Lower proportions of the Bacteriodetes phylum and higher Firmicutes in obese subjects compared to normal-weight subjects were first reported in the study of Ley et al. [121]. A decrease in Bacteroidetes and increase in Lactobacillus spp. within the Firmicutes phylum was also confirmed later [122]. An increased ratio of Firmicutes: Bacteriodetes in obese subjects was also confirmed by Verdam et al. [123]. Turnbaugh et al. [124] and Furet et al. [125] however found no change in Firmicutes with a decrease in Bacteroidetes (Bacteroides/Prevotella) in obese subjects. Whereas, Collado et al. [126] found increases in species level within both Firmicutes phylum (Staphylococcus aureus) and Bacteroidetes phylum (Bacteroides/Prevotella) in obese women. Some other studies also reported no changes in Bacteriodetes and Firmicutes between obese and normal-weight subjects [127-129]. Changes in these two phyla in obese subjects were not as consistent as those seen in high-fat-diet treated animal models. In addition, some studies also reported decreases, increases or no changes in Actinobacteria (the class in which Bifidobacterium spp. belongs) in obese subjects compared to healthy body mass index (BMI) subjects [124, 126, 127, 129-132]. These human studies indeed show that a high fat diet may impact on the microbiota composition and there are differences, although not well characterised, between obese and normal-weight subjects. In the future, studies of larger sample sizes should be conducted by applying standardised techniques and taking account of different factors, design studies such as age, sex, type and amounts of fat, and applied method used for DNA extraction and microbial quantification.

\subsection{Effects of the high fat diet on immune function}

A high fat diet can induce both intestinal and systemic inflammation in experimental animal models, as evidenced by the monitoring of inflammatory cytokines and mRNA expression, studies on this are summarised in Table 4.

According to Table 4, a high fat diet may lead to inflammation status and dysregulated immune response in the host by upregulating proinflammatory cytokines. Higher levels of TNF- $\alpha$, IL-1 and IL-6 and their mRNA expression levels in plasma and tissues following a high fat diet have been observed in animal models [15, 109, 114, 115, 117, 133, 134]. Similar changes in these proinflammatory cytokines have been observed in elderly populations, indicating that a high fat intake may be one factor driving such effects. Other immune system components are also affected by a high fat diet, leading to intestinal and systemic inflammation. For example, plasminogen activator inhibitor type $1, \mathrm{~F} 4 / 80$, proinflammatory cytokines MCP-1, and their mRNA levels have been 


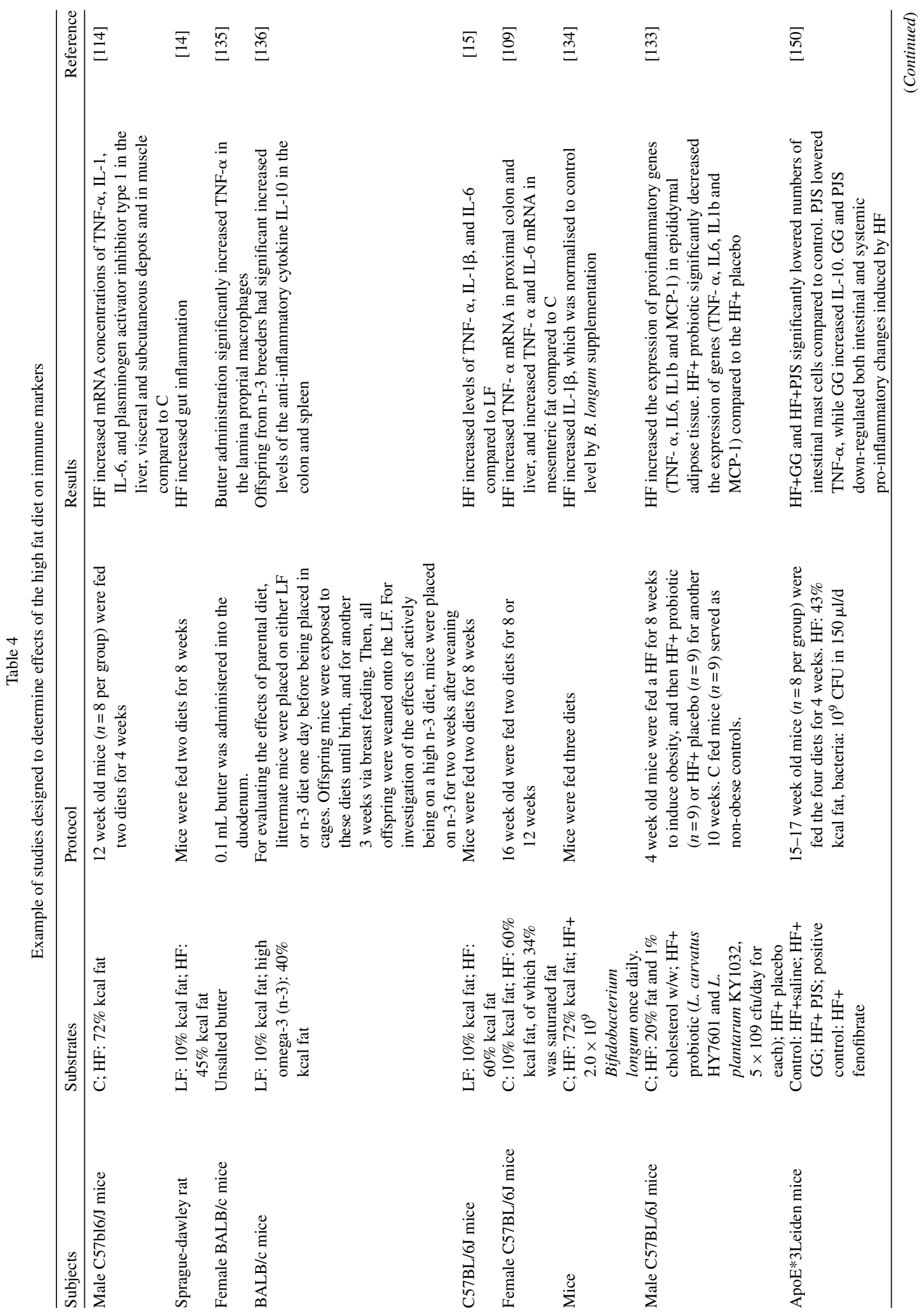




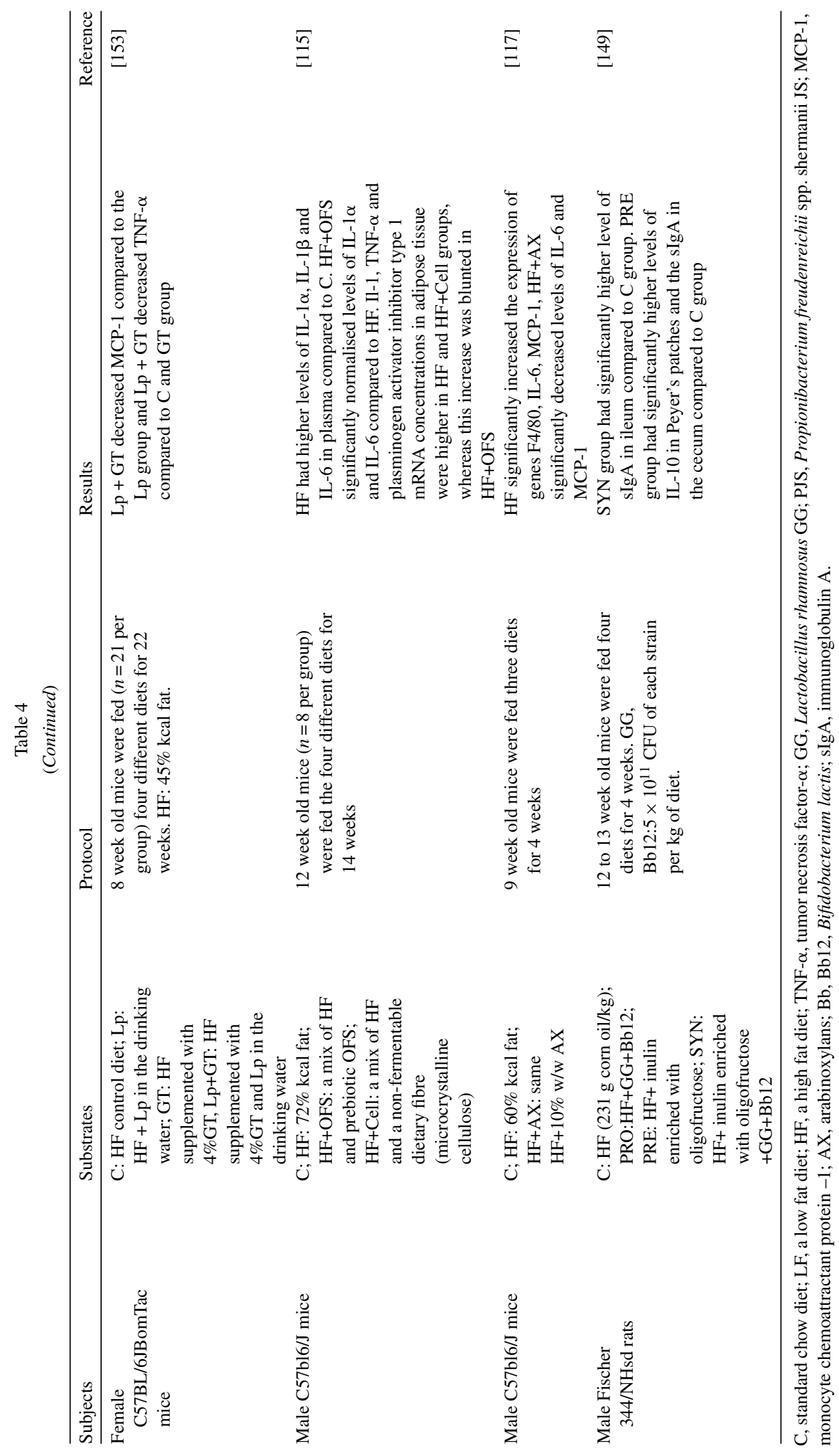


reported to be higher following a high fat diet [114, $115,117,133]$.

Most studies shown in Table 4 have focused on the impact of mixtures of fat and fatty acids, the specific types of fat may be relevant, as different types may have varying impacts on immune status. For example, unsalted butter rich in saturated fatty acids may upregulate inflammatory status by influencing proinflammatory cytokines [135]. However, a maternal high fat diet rich in omega-3 polyunsaturated fatty acids can down-regulate inflammation status and modulate immune function in mice offspring, by modulating the balance of proinflammatory and anti-inflammatory cytokines [136].

Although excessive maternal n-3 fatty acid intake has been shown to down-regulate inflammation status in mice offspring [136], most studies applying saturated and unsaturated fatty acid mixtures, have suggested that high fat feeding may contribute to gut and systemic inflammation, similarly immune function changes are also observed in elderly persons. The impact of a high fat diet on some immune markers in animal models are similar to those driven by the aging process in elderly. Therefore, there may be an association between high fat intake and immune function changes in elderly groups. In addition, these studies were conducted in experimental animal models rather than human beings, therefore, the effects of the high fat diet on immune function and the mechanisms still need to be confirmed further in human subjects.

\section{Mechanisms of high fat diet effects on microbiota composition and immune function}

The mechanism of how a high fat diet affects microbiota composition is not well known. When studying the effects of a high fat diet it is also important to control other factors, for example to make sure diets contain the same energy. Normally, a high fat diet is low in carbohydrate, while standard chow diet or a low fat diet is significantly higher in carbohydrate and fibre - the latter will also serve as substrate for microbiota growth. Therefore, results may be influenced by increased fat or decreased carbohydrate content [137]. It has been suggested that the effect of dietary fat on microbiota composition may be indirectly related to bile acids. To help fat digestion, bile salts emulsify lipids. With increasing fat intake, hepatic production and release of bile acids from the gallbladder to the small intestine is increased. Some gut microbiota components can convert $7 \alpha-$ dehydroxylate primary bile acids into secondary bile acids, which are potentially carcinogenic and related to colon cancer and gastrointestinal diseases [138, 139]. These bacteria normally represent a small proportion in the gut and consist of species belonging to the genus Clostridium [140].

A high fat diet could lead to inflammation and chronic disease via a few different pathways (Fig. 2). It has been suggested that alterations in the microbiota could lead to increased gut permeability following a high fat diet by decreasing mRNA expression of tight junction proteins including zona occludens-1 $[13,109]$. Alternations in microbiota composition could lead to elevated endotoxin production. With impaired gut barrier function, this would lead to increased lipopolysaccharide (LPS) translocation to plasma, which in turn triggers inflammation and may indicate metabolic disorder [14, 15, 114]. LPS, a component of Gram-negative bacterial cell walls, may bind to the CD14 toll-like receptor-4 (TLR-4) complex at the surface of innate immune cells to trigger an inflammatory process [141]. LPS absorption can be increased following a high fat diet. Dietary fat is transported from the gut as triglycerides into chylomicrons after incorporation. Chylomicrons have a high affinity with LPS; and therefore can carry and move LPS from the gut lumen into the circulatory system [142]. LPS can also be degraded by alkaline phosphatase. Intestinal alkaline phosphatase (IAP), is an intestinal brush border enzyme, mainly expressed on the surface of enterocyte microvillus membranes in the proximal small intestine [143]. The IAP is directly secreted into the intestinal lumen and bloodstream, with activity throughout the colon and within faeces [144]. Dietary fat content and fatty acids can affect this in different ways [14, 145, 146]. A decrease in IAP activity may decrease LPS degradation and increase circulating LPS levels [147].

In summary, due to changes in colonic microbiota, gut integrity, immune markers and their interactions following a high fat diet, disease risk may increase leading to a detrimental impact on host health.

\section{Can prebiotics and probiotics modulate changes induced by a high fat diet?}

As previously mentioned, changes in gut microbiota composition and immune markers driven by high fat diets in animal models are similar to those 


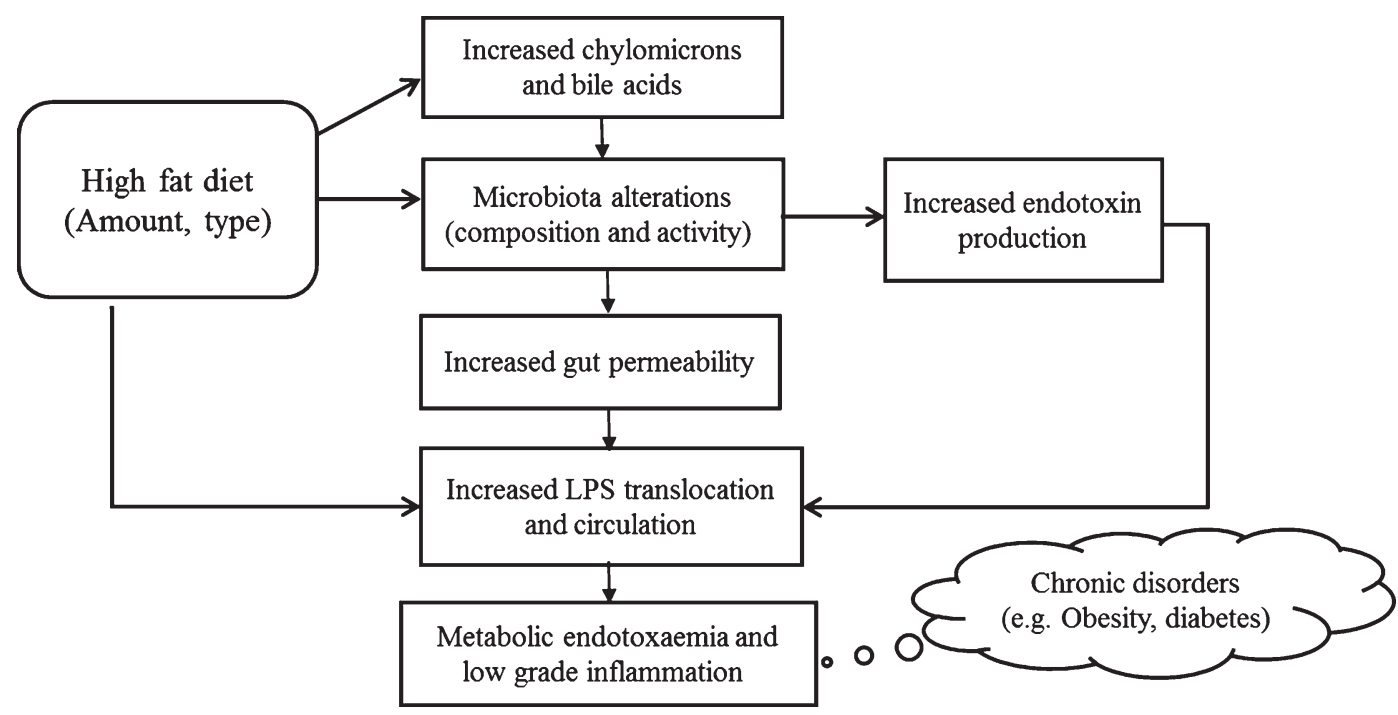

Fig. 2. Relationship between a high fat diet, microbiota composition and metabolic endotoxaemia. LPS, lipopolysaccharide. Adapted from [155].

driven by the aging process in elderly populations. Prebiotics and probiotics have been shown to modulate the microbiota composition and improve immune function in elderly populations. This presents the possibility that such interventions may counteract effects induced by a high fat diet in the elderly. Therefore, investigation is warranted to determine whether they could improve changes caused by a high fat diet in elderly populations.

\subsection{Modulation of microbiota composition}

As shown in Table 3, although the impact of a high fat diet on bifidobacteria is controversial, prebiotic supplementation can have positive effects. Prebiotics, including FOS, inulin-type fructans, and GOS were observed to increase bifidobacteria in several studies $[113,115,119]$. Other carbohydrates, with prebiotic properties, such as arabinoxylans can also have this potential [117, 119]. Changes in other bacteria induced by a high fat diet were also modulated and normalised by prebiotic supplementation [117, $119,148]$. In addition, prebiotics could regulate the balance of dominating bacteria, hence modulating microbiota equilibrium. In one study, the ratio of Firmicutes: Bacteriodetes was significantly lower following supplementation of GOS compared to that of a high-fat-diet treated group [148]. However, there was no low fat group in this study, which was a limitation of this experiment design.

\subsection{Modulation in immune function}

Prebiotics may modulate changes in immune function induced by a high fat diet through regulating immune markers including pro- and antiinflammatory cytokines (Table 4). In murine studies, oligofructose, inulin and arabinoxylans have shown this potential $[115,117,149]$. This provides the possibility of using prebiotics to modulate immune function in elderly people taking high fat diets.

Intestinal and systemic inflammation induced by high fat diets could also be down-regulated by different probiotic strains (Table 4). The impact of different probiotics has been tested and confirmed by a few murine studies. Well-studied probiotics include L. curvatus HY7601 and L. plantarum KY1032 [133], B. longum [134], L. rhamnosus GG and Propionibacterium freudenreichii spp. shermanii JS [150] (Table 4). These probiotics can downregulate both intestinal and systemic pro-inflammatory changes induced by a high-fat diet by reducing levels of some proinflammatory cytokines (TNF- $\alpha$, IL6, IL-1 $\beta$ ). Under high fat conditions, probiotics act to modulate immune markers in animal models, indicating the possibility to impact on immune function in elderly people consuming high fat diets. Synbiotics also have this potential. In the study of Roller et al. [149], a synbiotic combination of probiotics (Lactobacillus rhamnosus GG and Bifidobacterium lactis $\mathrm{Bb} 12$ ) and prebiotics (inulin enriched with oligofructose) could reduce systemic inflammation. 
In summary, a high fat diet has an impact on the microbiota composition and immune function in animal models (Tables 3 and 4). Some changes are similar to those induced by the aging process in elderly populations. Prebiotics, probiotics and synbiotics may modulate changes in the microbiota composition and immune function induced by a high fat diet (Tables 3 and 4). Therefore, it is possible that they could improve those changes induced by a high fat diet in elderly persons. A few possible mechanisms have been suggested, however they still need to be confirmed.

\section{Conclusion}

With an increasing aged population, more attention to elderly health status should be made. The aging process could lead to alterations in gut microbiota and dysregulation of immune function. These changes are similar to those induced by high fat intakes in animal models. Furthermore, elderly people have higher fat intakes than recommended levels, thus there may be an association between a high fat intake and dysfunctional aging processes. High fat diets may exasperate dysbiosis of gut microbiota and lead to impaired immune function. Hence, the elderly may be more vulnerable to disease risk, making the impact of fat on the gut microbiota important. Prebiotics and probiotics have been shown to have positive effects on microbiota composition, immune function and repress metabolic disorder in elderly, but mainly in animal models.

\section{References}

[1] Xu J, Gordon JI. Inaugural article: Honor thy symbionts. Proc Natl Acad Sci USA. 2003;100:10452-9.

[2] Eckburg PB, Bik EM, Bernstein CN, Purdom E, Dethlefsen L, Sargent M, Gill SR, Nelson KE, Relman DA. Diversity of the human intestinal microbial flora. Science. 2005;308(5728):1635-8.

[3] O'Hara AM, Shanahan F. The gut flora as a forgotten organ. EMBO Rep. 2006;7(7):688-93.

[4] Lupton JR. Microbial degradation products influence colon cancer risk: The butyrate controversy. J Nutr. 2004; 134(2):479-82.

[5] Roberfroid M, Gibson GR, Hoyles L, McCartney AL, Rastall R, Rowland I, Wolvers D, Watzl B, Szajewska H, Stahl B, Guarner F, Respondek F, Whelan K, Coxam V, Davicco MJ, Leotoing L, Wittrant Y, Delzenne NM, Cani PD, Neyrinck AM, Meheust A. Prebiotic effects: Metabolic and health benefits. Br J Nutr. 2010;104(Suppl 2):S1-63.
[6] Cummings JH. Short chain fatty acids in the human colon. Gut. 1981;22(9):763-79.

[7] Cummings JH. Human Colonic Bacteria: Role in Nutrition, Physiology and Pathology. Boca Raton, FL: CRC Press; 1995.

[8] Flint HJ. The significance of prokaryote diversity in the human gastrointestinal tract. In: Logan NA, Lappin-Scott HM, Oyston PCF, editors. Prokaryotic Diversity: Mechanisms and Significance. Cambridge, MA: Cambridge University Press; 2006, pp. 65-90.

[9] Nyangale EP, Mottram DS, Gibson GR. Gut microbial activity, implications for health and disease: The potential role of metabolite analysis. J Proteome Res. 2012;11(12):5573-85.

[10] Macfarlane S, Macfarlane GT. Proteolysis and amino acid fermentation. In: Gibson GR, Macfarlane GT, editors. Human colonic bacteria: Role in nutrition, physiology and pathology. Boca Raton, FL: CRC Press Inc.; 1995, pp. 75100.

[11] Butterworth RF. Pathophysiology of brain dysfunction in hyperammonemic syndromes: The many faces of glutamine. Mol Genet Metab. 2014;113(1-2):113-7.

[12] Chan AT, Giovannucci EL. Primary prevention of colorectal cancer. Gastroenterol. 2010;138(6):2029-43, e10.

[13] Cani PD, Bibiloni R, Knauf C, Waget A, Neyrinck AM, Delzenne NM, Burcelin R. Changes in gut microbiota control metabolic endotoxemia-induced inflammation in high-fat diet-induced obesity and diabetes in mice. Diabetes. 2008;57(6):1470-81.

[14] de La Serre CB, Ellis CL, Lee J, Hartman AL, Rutledge JC, Raybould HE. Propensity to high-fat diet-induced obesity in rats is associated with changes in the gut microbiota and gut inflammation. Am J Physiol Gastrointest Liver Physiol. 2010;299(2):G440-8.

[15] Kim KA, Gu W, Lee IA, Joh EH, Kim DH. High fat diet-induced gut microbiota exacerbates inflammation and obesity in mice via the TLR4 signaling pathway. PLoS One. 2012;7(10):e47713.

[16] Ellegård L, Andersson H, Bosaeus I. Rapeseed oil, olive oil, plant sterols, and cholesterol metabolism: An ileostomy study. Eur J Clin Nutr. 2005;59(12):1374-8.

[17] Ellegård L, Bosaeus I. Cholesterol absorption and excretion in ileostomy subjects on high- and low-dietary-cholesterol intakes. Am J Clin Nutr. 1994;59(1):48-52.

[18] Wiggins HS, Howell KE, Kellock TD, Stalder J. The origin of faecal fat. Gut. 1969;10(5):400-3.

[19] Gibson GR. The rise and rise of probiotics. The Biologist. 2005;52:95-8.

[20] FAO/WHO. Health and nutritional properties of probiotics in food including powder milk with live lactic acid bacteria. 2001 [Accessed 14th December 2011]. Available from: ftp://ftp.fao.org/docrep/fao/009/a0512e/a0512e00.pdf.

[21] FAO/WHO. Guidelines for the evaluation of probiotics in food 2002 [Accessed 14th December 2011]. Available from: ftp://ftp.fao.org/es/esn/food/wgreport2.pdf

[22] Gibson GR, Roberfroid MB. Dietary modulation of the human colonic microbiota: Introducing the concept of prebiotics. J Nutr. 1995;125(6):1401-12.

[23] Gibson GR, Scott KP, Rastall RA, Tuohy KM, Hotchkiss A, Dubert-Ferrandon A, Gareau M, Murphy EF, Saulnier D, Loh G, Macfarlane S, Delzenne N, Ringel Y, Kozianowski G, Dickmann R, Lenoir-Wijnkook I, Walker C, Buddington 
R. Dietary prebiotics: Current status and new definition. IFIS Functional Foods Bulletin. 2010;7:1-19.

[24] WHO. Facts about ageing 2014 [Accessed 30th January 2015]. Available from: http://www.who.int/ageing/ about/facts/en/

[25] Imahori K. How I understand aging. Nutr Rev. 1992; 50(12):351-2.

[26] Hodes RJ. Aging and the immune system. Immunol Rev. 1997;160:5-8.

[27] Lovat LB. Age related changes in gut physiology and nutritional status. Gut. 1996;38(3):306-9.

[28] Vulevic J, Drakoularakou A, Yaqoob P, Tzortzis G, Gibson GR. Modulation of the fecal microflora profile and immune function by a novel trans-galactooligosaccharide mixture (B-GOS) in healthy elderly volunteers. Am J Clin Nutr. 2008;88(5):1438-46.

[29] Doty RL, Shaman P, Applebaum SL, Giberson R, Siksorski L, Rosenberg L. Smell identification ability: Changes with age. Science. 1984;226(4681):1441-3.

[30] Karlsson S, Persson M, Carlsson GE. Mandibular movement and velocity in relation to state of dentition and age. J Oral Rehabil. 1991;18(1):1-8.

[31] Newton JP, Yemm R, Abel RW, Menhinick S. Changes in human jaw muscles with age and dental state. Gerodontology. 1993;10(1):16-22.

[32] Castell DO. Eating and swallowing disorders in the elderly. Pract Gastroenterol. 1988;12:32-43.

[33] Woodmansey EJ. Intestinal bacteria and ageing. J Appl Microbiol. 2007;102(5):1178-86.

[34] Kleessen B, Sykura B, Zunft HJ, Blaut M. Effects of inulin and lactose on fecal microflora, microbial activity, and bowel habit in elderly constipated persons. Am J Clin Nutr. 1997;65(5):1397-402.

[35] Yagamata A. Histopathological studies of the colon in relation to age. Jap J Gastroenterol. 1965;62:229-34.

[36] Brocklehurst JC. Bowel management in the neurologically disabled. The problems of old age. Proc R Soc Med. 1972; 65(1):66-9.

[37] Macfarlane GT, Cummings JH, Macfarlane S, Gibson GR. Influence of retention time on degradation of pancreatic enzymes by human colonic bacteria grown in a 3 -stage continuous culture system. J Appl Bacteriol. 1989;67(5): 520-7.

[38] Biagi E, Nylund L, Candela M, Ostan R, Bucci L, Pini E, Nikkila J, Monti D, Satokari R, Franceschi C, Brigidi P, De Vos W. Through ageing, and beyond: Gut microbiota and inflammatory status in seniors and centenarians. PLoS One. 2010;5(5):e10667.

[39] Woodmansey EJ, McMurdo ME, Macfarlane GT, Macfarlane S. Comparison of compositions and metabolic activities of fecal microbiotas in young adults and in antibiotic-treated and non-antibiotic-treated elderly subjects. Appl Environ Microbiol. 2004;70(10):6113-22.

[40] Stephen AM, Wiggins HS, Cummings JH. Effect of changing transit time on colonic microbial metabolism in man. Gut. 1987;28(5):601-9.

[41] Goodwin JS. Decreased immunity and increased morbidity in the elderly. Nutr Rev. 1995;53(4 Pt 2):S41-4; discussion S4-6.

[42] Butcher SK, Chahal H, Nayak L, Sinclair A, Henriquez NV, Sapey E, O'Mahony D, Lord JM. Senescence in innate immune responses: Reduced neutrophil phagocytic capac- ity and CD16 expression in elderly humans. J Leukoc Biol. 2001;70(6):881-6.

[43] Bruunsgaard H, Pedersen AN, Schroll M, Skinhoj P, Pedersen BK. Decreased natural killer cell activity is associated with atherosclerosis in elderly humans. Exp Gerontol. 2001;37(1):127-36.

[44] Agrawal A, Agrawal S, Tay J, Gupta S. Biology of dendritic cells in aging. J Clin Immunol. 2008;28(1):14-20.

[45] Min H, Montecino-Rodriguez E, Dorshkind K. Effects of aging on the common lymphoid progenitor to pro-B cell transition. J Immunol. 2006;176(2):1007-12.

[46] Haynes L, Swain SL. Why aging T cells fail: Implications for vaccination. Immunity. 2006;24(6):663-6.

[47] Pawelec G, Koch S, Franceschi C, Wikby A. Human immunosenescence: Does it have an infectious component? Ann N Y Acad Sci. 2006;1067:56-65.

[48] Hopkins MJ, Macfarlane GT. Changes in predominant bacterial populations in human faeces with age and with Clostridium difficile infection. J Med Microbiol. 2002;51(5):448-54.

[49] Mueller S, Saunier K, Hanisch C, Norin E, Alm L, Midtvedt T, Cresci A, Silvi S, Orpianesi C, Verdenelli MC, Clavel T, Koebnick C, Zunft HJ, Dore J, Blaut M. Differences in fecal microbiota in different European study populations in relation to age, gender, and country: A cross-sectional study. Appl Environ Microbiol. 2006;72(2): 1027-33.

[50] Zwielehner J, Liszt K, Handschur M, Lassl C, Lapin A, Haslberger AG. Combined PCR-DGGE fingerprinting and quantitative-PCR indicates shifts in fecal population sizes and diversity of Bacteroides, bifidobacteria and Clostridium cluster IV in institutionalized elderly. Exp Gerontol. 2009;44(6-7):440-6.

[51] Makivuokko H, Tiihonen K, Tynkkynen S, Paulin L, Rautonen N. The effect of age and non-steroidal antiinflammatory drugs on human intestinal microbiota composition. Br J Nutr. 2010;103(2):227-34.

[52] Gavini F, Cayuela C, Antoine J-M, Lecoq C, Lefebvre B, Membre J-M, Neut C. Differences in the distribution of bifidobacterial and enterobacterial species in human faecal microbiota of three (children, adults, elderly) age groups. Microb Ecol Health Dis. 2001;13:40-5.

[53] Hopkins MJ, Sharp R, Macfarlane GT. Age and disease related changes in intestinal bacterial populations assessed by cell culture, 16S rRNA abundance, and community cellular fatty acid profiles. Gut. 2001;48(2):198-205.

[54] Claesson MJ, Cusack S, O’Sullivan O, Greene-Diniz R, de Weerd H, Flannery E, Marchesi JR, Falush D, Dinan T, Fitzgerald G, Stanton C, van Sinderen D, O'Connor M, Harnedy N, O'Connor K, Henry C, O’Mahony D, Fitzgerald AP, Shanahan F, Twomey C, Hill C, Ross RP, O'Toole PW. Composition, variability, and temporal stability of the intestinal microbiota of the elderly. Proc Natl Acad Sci U S A. 2011;108(Suppl 1):4586-91.

[55] Mitsuoka T. Intestinal flora and aging. Nutr Rev. 1992; 50(12):438-46.

[56] Ouwehand AC, Isolauri E, Kirjavainen PV, Salminen SJ. Adhesion of four Bifidobacterium strains to human intestinal mucus from subjects in different age groups. FEMS Microbiol Lett. 1999;172(1):61-4.

[57] He F, Ouwehand AC, Isolauri E, Hosoda M, Benno Y, Salminen S. Differences in composition and mucosal adhe- 
sion of bifidobacteria isolated from healthy adults and healthy seniors. Curr Microbiol. 2001;43(5):351-4.

[58] Pryde SE, Duncan SH, Hold GL, Stewart CS, Flint HJ. The microbiology of butyrate formation in the human colon. FEMS Microbiol Lett. 2002;217(2):133-9.

[59] Louis P, Flint HJ. Diversity, metabolism and microbial ecology of butyrate-producing bacteria from the human large intestine. FEMS Microbiol Lett. 2009;294(1):1-8.

[60] Mariat D, Firmesse O, Levenez F, Guimaraes V, Sokol H, Dore J, Corthier G, Furet JP. The Firmicutes/Bacteroidetes ratio of the human microbiota changes with age. BMC Microbiol. 2009;9:123.

[61] Claesson MJ, Jeffery IB, Conde S, Power SE, O'Connor EM, Cusack S, Harris HM, Coakley M, Lakshminarayanan B, O’Sullivan O, Fitzgerald GF, Deane J, O'Connor M, Harnedy N, O'Connor K, O'Mahony D, van Sinderen D, Wallace M, Brennan L, Stanton C, Marchesi JR, Fitzgerald AP, Shanahan F, Hill C, Ross RP, O'Toole PW. Gut microbiota composition correlates with diet and health in the elderly. Nature. 2012;488(7410):178-84.

[62] Peterson CT, Sharma V, Elmen L, Peterson SN. Immune homeostasis, dysbiosis and therapeutic modulation of the gut microbiota. Clin Exp Immunol. 2014;179(3):363-77.

[63] Frank DN, St Amand AL, Feldman RA, Boedeker EC, Harpaz N, Pace NR. Molecular-phylogenetic characterization of microbial community imbalances in human Inflammatory Bowel Diseases. Proc Natl Acad Sci U S A. 2007;104(34):13780-5.

[64] Mondot S, Kang S, Furet JP, Aguirre de Carcer D, McSweeney C, Morrison M, Marteau P, Dore J, Leclerc M. Highlighting new phylogenetic specificities of Crohn's disease microbiota. Inflamm Bowel Dis. 2011;17(1): 185-92.

[65] Fujimoto T, Imaeda H, Takahashi K, Kasumi E, Bamba S, Fujiyama Y, Andoh A. Decreased abundance of Faecalibacterium prausnitzii in the gut microbiota of Crohn's disease. J Gastroenterol Hepatol. 2013;28(4):613-9.

[66] Jia W, Whitehead RN, Griffiths L, Dawson C, Waring RH, Ramsden DB, Hunter JO, Cole JA. Is the abundance of Faecalibacterium prausnitzii relevant to Crohn's disease? FEMS Microbiol Lett. 2010;310(2):138-44.

[67] Neuman MG. Immune dysfunction in inflammatory bowel disease. Transl Res. 2007;149(4):173-86.

[68] Magrone T, Jirillo E. The interaction between gut microbiota and age-related changes in immune function and inflammation. Immun Ageing. 2013;10(1):31.

[69] Bouhnik Y, Achour L, Paineau D, Riottot M, Attar A, Bornet F. Four-week short chain fructo-oligosaccharides ingestion leads to increasing fecal bifidobacteria and cholesterol excretion in healthy elderly volunteers. Nutr J. 2007;6:42.

[70] Guigoz Y, Rochat F, Perruisseau-Carrier G, Rochat I, Schiffrin EJ. Effects of oligosaccharide on the faecal flora and non-specific immune system in elderly people. Nutr Res. 2002;22(1-2):13-25.

[71] Walton GE, van den Heuvel EG, Kosters MH, Rastall RA, Tuohy KM, Gibson GR. A randomised crossover study investigating the effects of galacto-oligosaccharides on the faecal microbiota in men and women over 50 years of age. Br J Nutr. 2012;107(10):1466-75.

[72] Maukonen J, Mättö J, Kajander K, Mattila-Sandholm T, Saarela M. Diversity and temporal stability of fecal bacterial populations in elderly subjects consuming galacto-oligosaccharide containing probiotic yoghurt. Int Dairy J. 2008;18(4):386-95.

[73] Tzortzis G, Goulas AK, Gibson GR. Synthesis of prebiotic galactooligosaccharides using whole cells of a novel strain, Bifidobacterium bifidum NCIMB 41171. Appl Microbiol Biotechnol. 2005;68(3):412-6.

[74] Nagata S, Asahara T, Ohta T, Yamada T, Kondo S, Bian L, Wang C, Yamashiro Y, Nomoto K. Effect of the continuous intake of probiotic-fermented milk containing Lactobacillus casei strain Shirota on fever in a mass outbreak of norovirus gastroenteritis and the faecal microflora in a health service facility for the aged. Br J Nutr. 2011; 106(4):549-56.

[75] Ahmed M, Prasad J, Gill H, Stevenson L, Gopal P. Impact of consumption of different levels of Bifidobacterium lactis HN019 on the intestinal microflora of elderly human subjects. J Nutr Health Aging. 2007;11(1):26-31.

[76] Del Piano M, Ballare M, Montino F, Orsello M, Garello E, Ferrari P, Masini C, Strozzi GP, Sforza F. Clinical experience with probiotics in the elderly on total enteral nutrition. J Clin Gastroenterol. 2004;38(6 Suppl):S111-4.

[77] Ouwehand AC, Bergsma N, Parhiala R, Lahtinen S, Gueimonde M, Finne-Soveri H, Strandberg T, Pitkala K, Salminen S. Bifidobacterium microbiota and parameters of immune function in elderly subjects. FEMS Immunol Med Microbiol. 2008;53(1):18-25.

[78] Lahtinen SJ, Tammela L, Korpela J, Parhiala R, Ahokoski H, Mykkanen H, Salminen SJ. Probiotics modulate the Bifdobacterium microbiota of elderly nursing home residents. Age (Dordr). 2009;31(1):59-66.

[79] Tiihonen K, Ouwehand AC, Rautonen N. Human intestinal microbiota and healthy ageing. Ageing Res Rev. 2010; 9(2):107-16.

[80] Bartosch S, Woodmansey EJ, Paterson JC, McMurdo ME, Macfarlane GT. Microbiological effects of consuming a synbiotic containing Bifidobacterium bifidum, Bifidobacterium lactis, and oligofructose in elderly persons, determined by real-time polymerase chain reaction and counting of viable bacteria. Clin Infect Dis. 2005;40(1): 28-37.

[81] Ouwehand AC, Tiihonen K, Saarinen M, Putaala H, Rautonen N. Influence of a combination of Lactobacillus acidophilus NCFM and lactitol on healthy elderly: Intestinal and immune parameters. Br J Nutr. 2009;101(3): 367-75.

[82] Schiffrin EJ, Thomas DR, Kumar VB, Brown C, Hager C, Van't Hof MA, Morley JE, Guigoz Y. Systemic inflammatory markers in older persons: The effect of oral nutritional supplementation with prebiotics. J Nutr Health Aging. 2007;11(6):475-9.

[83] Bunout D, Hirsch S, Pia de la Maza M, Munoz C, Haschke F, Steenhout P, Klassen P, Barrera G, Gattas V, Petermann M. Effects of prebiotics on the immune response to vaccination in the elderly. JPEN J Parenter Enteral Nutr. 2002;26(6):372-6.

[84] Gill HS, Cross ML, Rutherfurd KJ, Gopal PK. Dietary probiotic supplementation to enhance cellular immunity in the elderly. Br J Biomed Sci. 2001;58(2):94-6.

[85] Gill HS, Rutherfurd KJ. Probiotic supplementation to enhance natural immunity in the elderly: Effects of a newly characterized immunostimulatory strain 
Lactobacillus rhamnosus HN001 (DR20 ${ }^{\mathrm{TM}}$ ) on leucocyte phagocytosis. Nutr Res. 2001;21:183-9.

[86] Gill HS, Rutherfurd KJ, Cross ML. Dietary probiotic supplementation enhances natural killer cell activity in the elderly: An investigation of age-related immunological changes. J Clin Immunol. 2001;21(4):264-71.

[87] Sheih YH, Chiang BL, Wang LH, Liao CK, Gill HS. Systemic immunity-enhancing effects in healthy subjects following dietary consumption of the lactic acid bacterium Lactobacillus rhamnosus HN001. J Am Coll Nutr. 2001;20(2 Suppl):149-56.

[88] Arunachalam K, Gill HS, Chandra RK. Enhancement of natural immune function by dietary consumption of Bifidobacterium lactis (HN019). Eur J Clin Nutr. 2000; 54(3):263-7.

[89] Chiang BL, Sheih YH, Wang LH, Liao CK, Gill HS. Enhancing immunity by dietary consumption of a probiotic lactic acid bacterium (Bifidobacterium lactis HN019): Optimization and definition of cellular immune responses. Eur J Clin Nutr. 2000;54(11):849-55.

[90] Gill HS, Rutherfurd KJ, Cross ML, Gopal PK. Enhancement of immunity in the elderly by dietary supplementation with the probiotic Bifidobacterium lactis HN019. Am J Clin Nutr. 2001;74(6):833-9.

[91] Binns N. Probiotics, prebiotics and the gut microbiota. ILSI Europe Concise Monograph Series. 2013:1-32.

[92] Satish Kumar R, Kanmani P, Yuvaraj N, Paari KA, Pattukumar V, Arul V. Lactobacillus plantarum AS1 binds to cultured human intestinal cell line HT-29 and inhibits cell attachment by enterovirulent bacterium Vibrio parahaemolyticus. Lett Appl Microbiol. 2011;53(4): 481-7.

[93] Kaewnopparat S, Dangmanee N, Kaewnopparat N, Srichana T, Chulasiri M, Settharaksa S. In vitro probiotic properties of Lactobacillus fermentum SK5 isolated from vagina of a healthy woman. Anaerobe. 2013;22:6-13.

[94] Blaut M. Relationship of prebiotics and food to intestinal microflora. Eur J Nutr. 2002;41(Suppl 1):I11-6.

[95] Burger-van Paassen N, Vincent A, Puiman PJ, van der Sluis M, Bouma J, Boehm G, van Goudoever JB, van Seuningen I, Renes IB. The regulation of intestinal mucin MUC2 expression by short-chain fatty acids: Implications for epithelial protection. Biochem J. 2009;420(2):211-9.

[96] Pullan RD, Thomas GA, Rhodes M, Newcombe RG, Williams GT, Allen A, Rhodes J. Thickness of adherent mucus gel on colonic mucosa in humans and its relevance to colitis. Gut. 1994;35(3):353-9.

[97] Anderson RC, Cookson AL, McNabb WC, Park Z, McCann MJ, Kelly WJ, Roy NC. Lactobacillus plantarum MB452 enhances the function of the intestinal barrier by increasing the expression levels of genes involved in tight junction formation. BMC Microbiol. 2010;10:316.

[98] Eun CS, Kim YS, Han DS, Choi JH, Lee AR, Park YK. Lactobacillus casei prevents impaired barrier function in intestinal epithelial cells. Apmis. 2011;119(1):49-56.

[99] Avonts L, De Vuyst L. Antimicrobial potential of probiotic lactic acid bacteria. Meded Rijksuniv Gent Fak Landbouwkd Toegep Biol Wet. 2001;66(3b):543-50.

[100] Ocaña VS, Pesce De Ruiz Holgado AA, Nader-Macias ME. Characterization of a bacteriocin-like substance produced by a vaginal Lactobacillus salivarius strain. Appl Environ Microbiol. 1999;65(12):5631-5.
[101] Medzhitov R. Recognition of microorganisms and activation of the immune response. Nature. 2007;449(7164): 819-26.

[102] Vance RE, Isberg RR, Portnoy DA. Patterns of pathogenesis: Discrimination of pathogenic and nonpathogenic microbes by the innate immune system. Cell Host Microbe. 2009;6(1):10-21.

[103] Sanderson IR. Dietary modulation of GALT. J Nutr. 2007;137(11 Suppl):2557s-62s.

[104] Kim MH, Kang SG, Park JH, Yanagisawa M, Kim $\mathrm{CH}$. Short-chain fatty acids activate GPR41 and GPR43 on intestinal epithelial cells to promote inflammatory responses in mice. Gastroenterol. 2013;145(2):396-406, e1-10.

[105] Park JS, Lee EJ, Lee JC, Kim WK, Kim HS. Antiinflammatory effects of short chain fatty acids in IFN-gamma-stimulated RAW 264.7 murine macrophage cells: Involvement of NF-kappaB and ERK signaling pathways. Int Immunopharmacol. 2007;7(1):70-7.

[106] Usami M, Kishimoto K, Ohata A, Miyoshi M, Aoyama M, Fueda Y, Kotani J. Butyrate and trichostatin A attenuate nuclear factor kappaB activation and tumor necrosis factor alpha secretion and increase prostaglandin E2 secretion in human peripheral blood mononuclear cells. Nutr Res. 2008;28(5):321-8.

[107] Saemann MD, Bohmig GA, Osterreicher CH, Burtscher H, Parolini O, Diakos C, Stockl J, Horl WH, Zlabinger GJ. Anti-inflammatory effects of sodium butyrate on human monocytes: Potent inhibition of IL-12 and up-regulation of IL-10 production. FASEB J. 2000;14(15):2380-2.

[108] Cox MA, Jackson J, Stanton M, Rojas-Triana A, Bober L, Laverty M, Yang X, Zhu F, Liu J, Wang S, Monsma F, Vassileva G, Maguire M, Gustafson E, Bayne M, Chou CC, Lundell D, Jenh CH. Short-chain fatty acids act as antiinflammatory mediators by regulating prostaglandin $\mathrm{E}(2)$ and cytokines. World J Gastroenterol. 2009;15(44):5549-57.

[109] Lam YY, Ha CW, Campbell CR, Mitchell AJ, Dinudom A, Oscarsson J, Cook DI, Hunt NH, Caterson ID, Holmes AJ, Storlien LH. Increased gut permeability and microbiota change associate with mesenteric fat inflammation and metabolic dysfunction in diet-induced obese mice. PLoS One. 2012;7(3):e34233.

[110] Bates B, Lennox A, Prentice A, Bates C, Swan G. National Diet and Nutrition Survey: Headline results from Years 1, 2 and 3 (combined) of the rolling programme (2008/2009 - 2010/11). 2012 [Accessed 12th August 2012]. Available from: https://www.gov.uk/government/statistics/ national-diet-and-nutrition-survey-headline-results-fromyears-1-2-and-3-combined-of-the-rolling-programme200809-201011.

[111] Drewnowski A, Almiron-Roig E. Human perceptions and preferences for fat-rich foods. In: Montmayeur JP, Le Coutre J, editors. Fat detection: Taste, texture, and post ingestive effects. Boca Raton, FL: CRC Press; 2010, pp. 265-91.

[112] Fava F, Gitau R, Griffin BA, Gibson GR, Tuohy KM, Lovegrove JA. The type and quantity of dietary fat and carbohydrate alter faecal microbiome and short-chain fatty acid excretion in a metabolic syndrome 'at-risk' population. Int J Obes (Lond). 2013;37(2):216-23.

[113] Respondek F, Gerard P, Bossis M, Boschat L, Bruneau A, Rabot S, Wagner A, Martin JC. Short-chain fructo- 
oligosaccharides modulate intestinal microbiota and metabolic parameters of humanized gnotobiotic diet induced obesity mice. PLoS One. 2013;8(8):e71026.

[114] Cani PD, Amar J, Iglesias MA, Poggi M, Knauf C, Bastelica D, Neyrinck AM, Fava F, Tuohy KM, Chabo C, Waget A, Delmee E, Cousin B, Sulpice T, Chamontin B, Ferrieres J, Tanti JF, Gibson GR, Casteilla L, Delzenne NM, Alessi MC, Burcelin R. Metabolic endotoxemia initiates obesity and insulin resistance. Diabetes. 2007;56(7):1761-72.

[115] Cani PD, Neyrinck AM, Fava F, Knauf C, Burcelin RG, Tuohy KM, Gibson GR, Delzenne NM. Selective increases of bifidobacteria in gut microflora improve highfat-diet-induced diabetes in mice through a mechanism associated with endotoxaemia. Diabetologia. 2007;50(11): 2374-83.

[116] Mozes S, Bujnáková D, Sefcíková Z, Kmet V. Developmental changes of gut microflora and enzyme activity in rat pups exposed to fat-rich diet. Obesity (Silver Spring). 2008;16(12):2610-5.

[117] Neyrinck AM, Possemiers S, Druart C, Van de Wiele T, De Backer F, Cani PD, Larondelle Y, Delzenne NM. Prebiotic effects of wheat arabinoxylan related to the increase in bifidobacteria, Roseburia and Bacteroides/Prevotella in diet-induced obese mice. PLoS One. 2011;6(6):e20944.

[118] Patrone V, Ferrari S, Lizier M, Lucchini F, Minuti A, Tondelli B, Trevisi E, Rossi F, Callegari ML. Short-term modifications in the distal gut microbiota of weaning mice induced by a high-fat diet. Microbiol. 2012;158(Pt 4):98392.

[119] Druart C, Neyrinck AM, Dewulf EM, De Backer FC, Possemiers S, Van de Wiele T, Moens F, De Vuyst L, Cani PD, Larondelle Y, Delzenne NM. Implication of fermentable carbohydrates targeting the gut microbiota on conjugated linoleic acid production in high-fat-fed mice. $\mathrm{Br} \mathrm{J}$ Nutr. 2013;110(6):998-1011.

[120] Mujico JR, Baccan GC, Gheorghe A, Díaz LE, Marcos A. Changes in gut microbiota due to supplemented fatty acids in diet-induced obese mice. Br J Nutr. 2013;110(4):711-20.

[121] Ley RE, Turnbaugh PJ, Klein S, Gordon JI. Microbial ecology: Human gut microbes associated with obesity. Nature. 2006;444(7122):1022-3.

[122] Armougom F, Henry M, Vialettes B, Raccah D, Raoult D. Monitoring bacterial community of human gut microbiota reveals an increase in Lactobacillus in obese patients and methanogens in anorexic patients. PLoS One. 2009;4(9): e7125.

[123] Verdam FJ, Fuentes S, de Jonge C, Zoetendal EG, Erbil R, Greve JW, Buurman WA, de Vos WM, Rensen SS. Human intestinal microbiota composition is associated with local and systemic inflammation in obesity. Obesity (Silver Spring). 2013;21(12):E607-15.

[124] Turnbaugh PJ, Hamady M, Yatsunenko T, Cantarel BL, Duncan A, Ley RE, Sogin ML, Jones WJ, Roe BA, Affourtit JP, Egholm M, Henrissat B, Heath AC, Knight R, Gordon JI. A core gut microbiome in obese and lean twins. Nature. 2009;457(7228):480-4.

[125] Furet JP, Kong LC, Tap J, Poitou C, Basdevant A, Bouillot JL, Mariat D, Corthier G, Doré J, Henegar C, Rizkalla S, Clément K. Differential adaptation of human gut microbiota to bariatric surgery-induced weight loss: Links with metabolic and low-grade inflammation markers. Diabetes. 2010;59(12):3049-57.
[126] Collado MC, Isolauri E, Laitinen K, Salminen S. Distinct composition of gut microbiota during pregnancy in overweight and normal-weight women. Am J Clin Nutr. 2008;88(4):894-9.

[127] Duncan SH, Lobley GE, Holtrop G, Ince J, Johnstone AM, Louis P, Flint HJ. Human colonic microbiota associated with diet, obesity and weight loss. Int J Obes (Lond). 2008;32(11):1720-4.

[128] Mai V, McCrary QM, Sinha R, Glei M. Associations between dietary habits and body mass index with gut microbiota composition and fecal water genotoxicity: An observational study in African American and Caucasian American volunteers. Nutr J. 2009;8:49.

[129] Jumpertz R, Le DS, Turnbaugh PJ, Trinidad C, Bogardus C, Gordon JI, Krakoff J. Energy-balance studies reveal associations between gut microbes, caloric load, and nutrient absorption in humans. Am J Clin Nutr. 2011;94(1): 58-65.

[130] Schwiertz A, Taras D, Schafer K, Beijer S, Bos NA, Donus C, Hardt PD. Microbiota and SCFA in lean and overweight healthy subjects. Obesity (Silver Spring). 2010;18(1): 190-5.

[131] Zhang H, DiBaise JK, Zuccolo A, Kudrna D, Braidotti M, Yu Y, Parameswaran P, Crowell MD, Wing R, Rittmann BE, Krajmalnik-Brown R. Human gut microbiota in obesity and after gastric bypass. Proc Natl Acad Sci U S A. 2009; 106(7):2365-70.

[132] Million M, Maraninchi M, Henry M, Armougom F, Richet H, Carrieri P, Valero R, Raccah D, Vialettes B, Raoult D. Obesity-associated gut microbiota is enriched in Lactobacillus reuteri and depleted in Bifidobacterium animalis and Methanobrevibacter smithii. Int J Obes (Lond). 2012;36(6):817-25.

[133] Park DY, Ahn YT, Park SH, Huh CS, Yoo SR, Yu R, Sung MK, McGregor RA, Choi MS. Supplementation of Lactobacillus curvatus HY7601 and Lactobacillus plantarum KY1032 in diet-induced obese mice is associated with gut microbial changes and reduction in obesity. PLoS One. 2013;8(3):e59470.

[134] Chen JJ, Wang R, Li XF, Wang RL. Bifidobacterium longum supplementation improved high-fat-fed-induced metabolic syndrome and promoted intestinal Reg I gene expression. Exp Biol Med (Maywood). 2011;236(7):823-31.

[135] Fujiyama Y, Hokari R, Miura S, Watanabe C, Komoto S, Oyama T, Kurihara C, Nagata H, Hibi T. Butter feeding enhances TNF-alpha production from macrophages and lymphocyte adherence in murine small intestinal microvessels. J Gastroenterol Hepatol. 2007;22(11): 1838-45.

[136] Myles IA, Pincus NB, Fontecilla NM, Datta SK. Effects of parental omega-3 fatty acid intake on offspring microbiome and immunity. PLoS One. 2014;9(1):e87181.

[137] Scott KP, Gratz SW, Sheridan PO, Flint HJ, Duncan SH. The influence of diet on the gut microbiota. Pharmacol Res. 2013;69(1):52-60.

[138] Ou J, DeLany JP, Zhang M, Sharma S, O'Keefe SJ. Association between low colonic short-chain fatty acids and high bile acids in high colon cancer risk populations. Nutr Cancer. 2012;64(1):34-40.

[139] Ridlon JM, Kang DJ, Hylemon PB. Bile salt biotransformations by human intestinal bacteria. J Lipid Res. 2006; 47(2):241-59. 
[140] Wells JE, Williams KB, Whitehead TR, Heuman DM, Hylemon PB. Development and application of a polymerase chain reaction assay for the detection and enumeration of bile acid 7alpha-dehydroxylating bacteria in human feces. Clin Chim Acta. 2003;331(1-2):127-34.

[141] Musso G, Gambino R, Cassader M. Obesity, diabetes, and gut microbiota: The hygiene hypothesis expanded? Diabetes Care. 2010;33(10):2277-84.

[142] Ghoshal S, Witta J, Zhong J, de Villiers W, Eckhardt E. Chylomicrons promote intestinal absorption of lipopolysaccharides. J Lipid Res. 2009;50(1):90-7.

[143] Geddes K, Philpott DJ. A new role for intestinal alkaline phosphatase in gut barrier maintenance. Gastroenterol. 2008;135(1):8-12.

[144] Alpers DH, Zhang Y, Ahnen DJ. Synthesis and parallel secretion of rat intestinal alkaline phosphatase and a surfactant-like particle protein. Am J Physiol. 1995;268(6 Pt 1):E1205-14.

[145] Kaur J, Madan S, Hamid A, Singla A, Mahmood A. Intestinal alkaline phosphatase secretion in oil-fed rats. Dig Dis Sci. 2007;52(3):665-70.

[146] Vázquez CM, Zanetti R, Santa-Maria C, Ruiz-Gutierrez V. Effects of two highly monounsaturated oils on lipid composition and enzyme activities in rat jejunum. Biosci Rep. 2000;20(5):355-68.

[147] Delzenne NM, Neyrinck AM, Cani PD. Modulation of the gut microbiota by nutrients with prebiotic properties: Consequences for host health in the context of obesity and metabolic syndrome. Microb Cell Fact. 2011;(10 Suppl 1):S10.

[148] Serino M, Luche E, Gres S, Baylac A, Berge M, Cenac C, Waget A, Klopp P, Iacovoni J, Klopp C, Mariette J, Bouchez O, Lluch J, Ouarne F, Monsan P, Valet P, Roques C, Amar J, Bouloumie A, Theodorou V, Burcelin R. Metabolic adaptation to a high-fat diet is associated with a change in the gut microbiota. Gut. 2012;61(4):543-53.
[149] Roller M, Rechkemmer G, Watzl B. Prebiotic inulin enriched with oligofructose in combination with the probiotics Lactobacillus rhamnosus and Bifidobacterium lactis modulates intestinal immune functions in rats. J Nutr. 2004;134(1):153-6.

[150] Oksaharju A, Kooistra T, Kleemann R, van Duyvenvoorde W, Miettinen M, Lappalainen J, Lindstedt KA, Kovanen PT, Korpela R, Kekkonen RA. Effects of probiotic Lactobacillus rhamnosus GG and Propionibacterium freudenreichii ssp. shermanii JS supplementation on intestinal and systemic markers of inflammation in ApoE*3Leiden mice consuming a high-fat diet. Br J Nutr. 2013;110(1):77-85.

[151] Turchet P, Laurenzano M, Auboiron S, Antoine JM. Effect of fermented milk containing the probiotic Lactobacillus casei $\mathrm{DN}-114001$ on winter infections in free-living elderly subjects: A randomised, controlled pilot study. J Nutr Health Aging. 2003;7(2):75-7.

[152] Everard A, Belzer C, Geurts L, Ouwerkerk JP, Druart C, Bindels LB, Guiot Y, Derrien M, Muccioli GG, Delzenne NM, de Vos WM, Cani PD. Cross-talk between Akkermansia muciniphila and intestinal epithelium controls diet-induced obesity. Proc Natl Acad Sci U S A. 2013;110(22):9066-71.

[153] Axling U, Olsson C, Xu J, Fernandez C, Larsson S, Strom K, Ahrne S, Holm C, Molin G, Berger K. Green tea powder and Lactobacillus plantarum affect gut microbiota, lipid metabolism and inflammation in high-fat fed C57BL/6J mice. Nutr Metab (Lond). 2012;9(1):105.

[154] Rehman T. Role of the gut microbiota in age-related chronic inflammation. Endocr Metab Immune Disord Drug Targets. 2012;12(4):361-7.

[155] Moreira AP, Texeira TF, Ferreira AB, Peluzio Mdo C, Alfenas Rde C. Influence of a high-fat diet on gut microbiota, intestinal permeability and metabolic endotoxaemia. $\mathrm{Br} \mathrm{J}$ Nutr. 2012;108(5):801-9. 